\title{
An educational programme to facilitate reflective practice of registered nurses in training hospitals in Windhoek
}

\author{
L. N. Nelumbu *, A. van Dyk \\ University of Namibia; Private Bag 13301; Windhoek; Namibia \\ *Corresponding author E-mail: Inelumbu@unam.na
}

\begin{abstract}
Problems or incidents occurring in clinical settings are often seen as indicators of poor nursing care and even indicators of a lack of reflective practice skills. In the hope of improving such situations a qualitative, explorative, phenomenological, descriptive and contextual approach was conducted to explore and describe how reflective practice is practised by registered nurses in training hospitals in Windhoek. The findings of this study revealed inadequate knowledge of reflective practice among registered nurses. This paper represents the findings of situational analysis of the experiences of registered nurses on reflective practice.
\end{abstract}

Keywords: Facilitate, Reflection, Reflection-In-Action, Reflection-on-Action, Reflective Practice.

\section{Background}

Illness is an inevitable part of life for the vast majority of people. The nurses' reactions to people who are ill or who are in need of health care are influenced and shaped by their own personal qualities, such as sensitivity, understanding and honesty, as well as the professional attributes, skills, competencies, attitudes and cognitive abilities necessary for effective practice.

A profession, in order to continually develop as a discipline, needs to generate knowledge that can evolve from education and practice. It is also expected that professional nurses be competent practitioners able to render quality care. This implies that nurse practitioners must have critical analytical thinking abilities as well as empathy and moral values (van Vuuren and Botes, 1999). One of the processes that can accommodate these thinking skills is reflective practice.

The concept of reflective practice has been described in literature but it may not be known to all concerned and is also not rigorously tested or applied in practice. Dewey (as cited in Kinsella 2009) viewed reflection as an important aim of education and believed that people should acquire the general habit of reflecting. Furthermore, the concept of reflection also had an influence on nursing education which provides a foundation for reflection on nursing practice worldwide in terms of the developing expertise of nurses in action.

Schön (cited in Bulman \& Schutz, 2004, p. 2) identified two types of reflection-reflection-in-action and reflection-on-actionwhich he defines as follows: 'reflection-in-action' happens where we may reflect in the midst of action without interrupting it. In other words our thinking serves to reshape what we are doing while we are doing it, while reflection-on-action is: "thinking back on what we have done in order to discover how our knowing in action may have contributed to an unexpected outcome."

It is currently not clear whether professional nurses in Namibia exercise reflective practice during their daily practices or not. This concern is raised by some incidents that often occurred in clinical settings which could be an indication of poor application of reflection. Reports of patients receiving poor nursing care, as well as unethical treatment by nurses, seem to be common. This type of behaviour leads not only to disciplinary hearings, as reported by the Nursing Council of Namibia, but also to a decline in quality of nursing care, which has a detrimental effect on the image of the nursing profession.

Concerning the above mentioned challenges the following questions are asked:

- "Do registered nurses reflect on their daily practices and how do they do it?"

- "How can reflective practice in nursing care be facilitated?"

\section{Purpose}

The purpose of the study was to explore and describe whether reflective practice is demonstrated in practicing nursing, and to develop, implement and evaluate an educational programme which can facilitate reflective practice for registered nurses in order to improve the provision of nursing care.

\section{Study design and methods}

A qualitative, phenomenological and contextual design was selected for the study to explore and describe the experience of registered nurses on the concept of reflective practice and how they reflect on their experiences in their daily practice. The sample size entailed 15 registered nurses from the disciplines, namely: Surgery, Gynaecology and Obstetrics, Internal Medicine, Paediatrics and Orthopaedics were purposefully selected from both hospitals. The sampling criterion used for this study was confined to registered nurses who have two (2) or more years of experience in the field and who would thus be a valuable source of information for this study. The data were collected using in-depth interviews. The data were collected until saturation point was reached (Polit \& 
Beck, 2012) and were analysed according to the Tesch model of qualitative data analysis (De Vos et al. 2007, Creswell, 2008).

\section{The findings}

The findings of the study revealed a poor understanding on reflective practice among the registered nurses who participated in the study. Three themes were identified from the data analysis. The first theme is related to the participants' concerns and attributes of caring on their daily practices. The second theme is related to the participants' experiences of different emotions during reflection and expression of their meaning. The third theme is related to participants' reflection on resolutions concerning challenges in their daily practice.

\section{Discussion on themes and the literature con- trol}

Theme 1: Participants reflected on their daily practices and experienced concerns and attributes of caring.

This theme focuses on the different concerns of the nurses surrounding the concept of reflective practice and the obstacles which impact on its fulfilment in their daily practice as well as their achievements. It was found that registered nurses usually reflect on their concerns, challenges and specific achievements within the clinical setting, based on the principles of reflective practice. However, not all participants reflect effectively. If the registered nurses do not reflect effectively on their daily practices, it implies that they cannot invent new approaches to address clinical problems, or develop principles of self-evaluation (Bulman \& Schutz, 2004; Lyons, 1999).

In this study it was found that the participants had experienced concerns and attributes of caring in their daily practice, which came out during reflection. The following sub-themes were identified as factors or concerns contributing to the poor reflection of registered nurses as well as how their specific attributes of caring affect the patients positively in their daily practice.

Sub-theme 1: Participants did not always experience a proper sense of responsibility concerning their roles and function.

This is evidenced by the following response from some of the participants.

"As a registered nurse I do reflect but I do not do observations properly because of many patients."

"I just use shortcuts in order to finish the tasks for example if I happened to be in a full and busy ward I sometimes find myself moving from one patient to another without washing my hands in between."

"As a registered nurse, I have noticed that some patients receive their medicines early and some late which affects patients negatively."

"When the ward is full the procedures are also slow, for example, administration of medicine which sometimes prevents me from reflecting properly on what I did or should do."

It has been attested by other researchers that a professional nursing practice environment characterized by quality leadership and management, sufficient staffing, positive nurse-physician relationship, reasonable workload and appropriate working conditions is required to ensure and sustain high quality patient care (van Bogaert; Meulemans; Clarke; Vermeyen; and De Heyning, 2009). Some of the participants had this to say:

"I try to teach new staff even though time is against me because I believe that this is part of my responsibility."

Professional teaching in nursing education is an intentional enterprise that aims to facilitate learning, so that students can develop the appropriate knowledge and skills that would enable them to deliver high quality care to patients (Quinn 2007).

Some participants pointed out the following:
"When I am off duty and recall an uncompleted task meant for a patient I immediately call my colleagues who are on duty and ask them to complete it."

According to the participants' explanations, uncompleted tasks refer to tasks left undone after the nurses ended their daily shifts, for example unattended wound dressings. Uncompleted tasks were categorised as some of the factors which influence the registered nurses to do reflection positively.

Sub-theme 2: during reflective interviews the following attributes were indicated:

The following sub-themes were identified where the participants commented on their different determinations and commitments to meeting the needs of patients: prioritising of nursing care, record keeping and report giving, serving as a role model, maintaining proper communication, clinical supervision, giving advice and acting during emergency cases. The participants indicated that they try to maintain the hygiene of the patients and their environment, feeding them and maintaining their social, physical and psychological wellbeing.

To conclude, the participants revealed that they do reflect on meeting patients' social, physical and psychological needs in order to see them returning home healthy and satisfied.

Some of the participants had this to say:

"I usually try to prioritise the conditions, with the understanding that patients in critical conditions should receive treatment and nursing care first."

Some participants indicated that they usually try to prioritise the conditions, with the understanding that patients in critical condition should receive treatment and nursing care first in order to save their lives.

The above attribute is supported by Odell, et al. (2009) that effective observation of ward patients is the first key step in identifying patients whose condition is deteriorating and effectively managing their care.

Record keeping was one of the attributes the participants mentioned and was indicated as following:

"When I finish treating the patient I always go back and check if I have recorded all the activities in the patient's file which is important for my colleagues to know about the patients' progress and activities performed and to be done."

The importance of record keeping and report giving is to ensure that all staff members fully understand the nursing care required for each patient. Registered nurses and other health professionals always need to consider the importance of record keeping, such as the recording of any special factors that appear to affect the patient or the patient's response to treatment, as well as to aid communication between the team members (Pullen \& Loudon, 2006).

To conclude this attribute we can state that some of the registered nurses are trying to reflect on record keeping by going back and checking if they have recorded all the activities in the patient's file, as it is important for colleagues to know about the patient's progress and activities already performed and those yet to be done. To be a role model is an attribute which is essential for each health care provider. Some of the participants mentioned the following:

"My focus is to be a role model, acting in a polite way and respecting the patients and colleagues."

"I try to be a role model for my colleagues and wish them to do the same."

Some participants reflected and pointed out that one of their roles is to be a role model, acting in a polite way and respecting patients and colleagues and wishing others to do the same. Role-modelling was also described by Myrick, Yonge and Billay (2009) as the key to doing good in the moment which implies a particular individual style, behaviour, way of speaking and thinking one would inevitably like to emulate.

Theme 2: Participants experienced different emotions during reflection and expressed their meaning

'Emotion' is defined in the Oxford Dictionary as "the part of a person's character that consists of feelings".

Sub-theme 1: Positive emotions were experienced by participants as discussed below 
The participants in this research indicated that they experience emotions of happiness, self-worth and encouragement when they have completed their work and reflected on it. Some reflected as follows:

"I expect the patients to be happy about my activities and this encourages me to do and love my work."

According to the theory of positive emotions, positive emotions do not merely reflect momentary happiness or satisfaction, but, more importantly, serve the evolutionary adaptive function of widening a person's scope of attention and cognition as well as expanding the array of possible behaviours (Abe, 2011).

"I believe that the cure of a patient is mainly based on loving care."

"My focus is to be friendly and feel empathy towards the patients and colleagues."

Empathy is the ability to identify the effective emotional message sent by someone else and to acknowledge it verbally.

One can conclude that the focus of registered nurses is to be friendly and to feel empathy toward the patients and colleagues. Thus the provision of loving care to patients has been observed by some participants as mentioned above.

Sub-theme 2: Negative emotions were experienced by participants as discussed below:

Some of the negative emotions were feelings of incompetence as well as frustration. Participants reflected on guilty feelings experienced when there was incompletion of duties.

"When I am off-duty I still feel guilty if I did not complete everything for the patient because of time."

"I feel bad when I did not do what I was supposed to do. For example when I observed that a patient looks pale it means that need to do the haemoglobin test immediately, but because of an overload I may do it later."

It was reflected and mentioned by the participants that when there is conflict among them as colleagues they usually try to communicate with one another so that they can understand each other and work as a team.

"When there is a conflict among us as colleagues I always try to communicate with my colleagues so that we can understand each other and work as a team."

'Conflict' is defined in the Oxford Dictionary as "a situation in which people, groups or countries are involved in a serious disagreement or argument". Understanding can result in decreased judgment and in recognition of different values, experiences and priorities. It can also reveal points of agreement that often serve as common ground for moving forward (York-Barr et al., 2006).

Some participants experienced stress as a result of many factors.

"Due to stress caused by a sometimes unmanageable workload, I realised that I am not able to assist every patient as intended."

Gibbons, Dempster and Moutray (2009) supported this saying that the main clinical sources of stress for nurses and student nurses include working with dying patients, conflicts with other staff, insecurity about one's clinical competence, interpersonal problems with patients and heavy workload.

Theme 3: Participants reflected on resolutions concerning challenges in their daily practice

In order to achieve the aim of nursing care, the provision of quality care should be based on appropriate theory and its proper application practice, the vehicle being reflective practice.

Sub-theme 1: Reflection on resolutions to challenges was highlighted.

"I always try to reflect and think of the situation in order to improve it, for example, to provide the quality patient care."

"When I am giving treatment to a patient I always ask myself whether the treatment I am giving would help him or not." With the above statements in mind one needs to look at the study of Fields, Tedeschi, Foltz, Myers, Heaney, Bosak, et al. (2008) on reducing preventable medication safety events and recognize the renal risk caused by certain medications when administered erroneously, especially to elderly women who are more likely to have hidden renal risks.
To conclude theme three and its sub themes, the registered nurses indicated how they reflected on the provision of nursing care embracing their role in administering medicine to the patients. It was found that registered nurses have resolved to provide quality care and this can only be achieved when these professionals engage in both "reflection-in-action" and "reflection-on-action" in their daily practice.

\section{Conclusion}

The outcome of this analysis has identified the participants' definitions of reflective practice, and the factors that affect the application of reflective practice both negatively and positively. Registered nurses sometimes could not perform their duties as expected due to a variety of reasons which range from understaffing, unrealistic patient-nurse ratio in the wards and insufficient time. Some registered nurses had difficulty reflecting upon the complexity of their roles.

\section{Recommendations}

Key recommendations were made with regard to the objective on exploration and description of reflection practiced by registered nurses. Nurse educators should use scenarios during clinical simulations to prepare students in practice-based professions so that this becomes an important educational strategy to facilitate learning. Nurse educators need to use various strategies to facilitate the development of students into reflective practitioners. The staff development unit in training hospitals needs to introduce a variety of methods to help registered nurses to apply reflective practice in clinical practice. It is important that senior registered nurses or supervisors in the clinical setting should prepare clear guidelines and appropriate rosters to assist new staff and students to develop the requisite knowledge and practices to ensure good patient care outcomes. Reflective diaries are also important. Registered nurses should be encouraged to keep reflective diaries. These can be used to evaluate events in their daily practice, to describe the events in their practice, to reflect on what may become routine and to develop and evaluate the action taken. Hospital management and training institutions should set up standards for practice to improve the nursing situation and to address the shortage of staff in the units/wards.

\section{Acknowledgements}

The study was conducted with the permission of the Ethical and Research Committee of the Ministry of Health and Social Services in Namibia. Special thanks are extended to all the registered nurses who participated in this study for making themselves available in spirit of sharing their experiences and perceptions on the important concept which is reflective practice. As the primary source of data they were fundamental to the success of this study.

\section{References}

[1] Abe, J. A. A. (2011). Positive emotions, emotional intelligence, and successful experiential learning. Personality and Individual Differences, 51(7), 817-822. http://dx.doi.org/10.1016/j.paid.2011.07.004.

[2] Bulman, C. \& Schutz, S. (2004). Reflective practice in nursing. Oxford: Blackwell Publishing.

[3] Creswell, J, W. (2008). Educational research: Planning, conducting and evaluating qualitative \& quantitative research (4th Ed.). New Jersey: Pearson Education.

[4] De Vos, A. S., Strydom, H., Fouche, C.B. \& Delport, C.S.L. (2007). Research at grass roots for the social sciences and human service professions. Pretoria: Van Schaik Publishers.

[5] Fields, W., Tedeschi, C., Foltz, J., Myers, T., Heaney, K., Bosak, K. Rizos A. \& Syner, R. (2008). Reducing preventable medication safety events: Clinical nurse specialist. Journal of Advanced Nursing, 22(2), 73-78. 
[6] Gibbons, C. Dempster, M. \& Moutray, M. (2009). Surveying nursing students on their sources of stress: A validation study. Nurse Educa$\begin{array}{lll}\text { tion } & \text { Today. } & \text { 29(8), }\end{array}$ http://dx.doi.org/10.1016/j.nedt.2009.04.008.

[7] Kinsella, E. A. (2009). Professional knowledge and the epistemology of reflective practice. Nursing Philosophy, 11(1), 3-14. http://dx.doi.org/10.1111/j.1466-769X.2009.00428.x.

[8] Lyons, J. (1999). Reflective education for professional practice: Discovering knowledge from experience. Nurse Education Today, 19(1), 29-34. http://dx.doi.org/10.1054/nedt.1999.0607.

[9] Myrick, F., Yonge, O. \& Billay, D. (2009). Preceptorship and practical wisdom: A process of engaging in authentic nursing practice. Nurse Education in Practice, 10(2), 82-87. http://dx.doi.org/10.1016/j.nepr.2009.03.018.

[10]Odell, M. Victor, C. \& Oliver, D. (2009). Nurses' role in detecting deterioration in ward patients: Systematic literature review. Journal of Advanced Nursing 65(10), 1992-2006. http://dx.doi.org/10.1111/j.1365-2648.2009.05109.x. Oxford Dictionary (2005) Oxford: University Press.

[11]Polit, D. F \& Beck, C. T. (2012). Nursing Research: Generating and Assessing Evidence for Nursing Practice. Philadelphia: Lippincott Williams and Wilkins.

[12]Pullen, I \& Loudon, J. (2006). Improving standards in clinical record keeping. Advances in Psychiatric Treatment, 12(4), 280-286. http://dx.doi.org/10.1192/apt.12.4.280.

[13]Quinn, F. M. (2007). Principles and Practice of Nurse Education. Cheltenham: Stanley Thornes.

[14]Van Bogaert, P., Meulemans, H., Clarke, S., Vermeyen, K. \& van De Heyning, P. (2009). Hospital Nurse practice environment burnout, job outcomes and quality of care: Test of a structural equation model. Journal of Advanced Nursing, 65(10), 2175-2185. http://dx.doi.org/10.1111/j.1365-2648.2009.05082.x.

[15]Van Vuuren, M. \& Botes, A. (1999). Concept analysis of reflective thinking. Curations, 22(3), 25-35.

[16]York-Barr, J., Sommers, W. A. \& Ghere, G. S. (2006). Reflective Practice to improve schools: An action guide for educators. California: Corwin. 